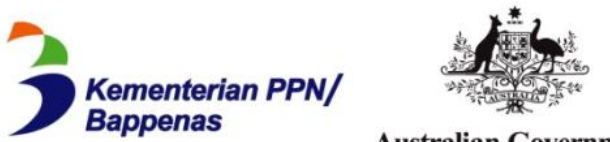
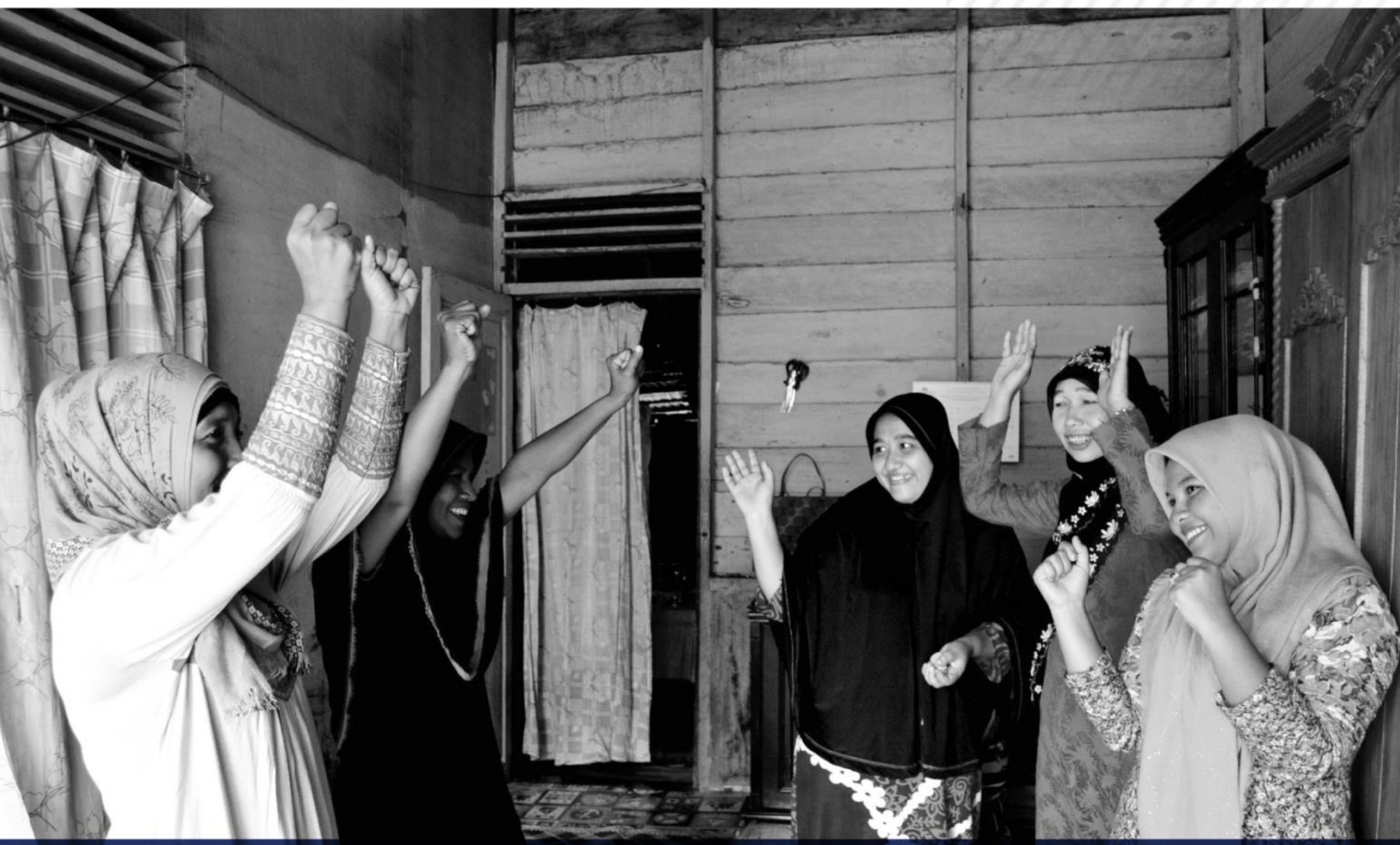

\title{
RESEARCH AND POLICY BRIEF
}

Gender-Inclusive Development and Decentralised

Governance: Promoting Women's Voice and Influence through Collective Action in Rural Indonesia 
This research was supported by the Governments of Australia and Indonesia and was conducted in consultation with the civil society organisations involved. We would like to thank these organisations and the Australia-Indonesia Partnership for Women's Empowerment and Gender Equality (MAMPU) for their support, as well as the many participants in the research, in particular the countless village women who shared their experiences and views with us. We would also like to thank the reviewers, and the many people who provided feedback through workshops, seminars, webinars, and other discussions. The views expressed in the analysis are those of the authors alone and do not necessarily reflect the views of the supporting governments or organisations.

To cite this research and policy brief: Diprose, R., A. Savirani, and T. Wells, 2020. Gender-inclusive Development and Decentralised Governance: Promoting Women's Voice and Influence through Collective Action in Rural Indonesia. Research and Policy Brief 1. The University of Melbourne, Universitas Gadjah Mada and MAMPU. https://doi.org/10.46580/124335. Available at: www.mampu.or.id and www.demisetara.org. 
This brief presents findings and recommendations for agencies and organisations seeking to support women's collective influence on governance, development and broader structures of power in rural Indonesia, with a particular emphasis on the implementation the Village Law and interrelated district influence and policy making.

The brief draws on research conducted by The University of Melbourne and Universitas Gadjah Mada (the University of Gadjah Mada) on Women's Collective Action and the Village Law in Indonesia. The study draws from mixed-methods qualitative research involving more than 600 participants (backed up by additional quantitative data), predominantly women and those in more vulnerable situations, in nine provinces, 12 districts, and 14 villages - from Sumatra, to East and West Nusa Tenggara, Kalimantan, Sulawesi, and Java.

The brief provides an overview of key messages, a background to the Women's Collective Action and the Village Law study, and then outlines $\mathbf{1 2}$ core findings and $\mathbf{1 0}$ related key recommendations. Drawing on the research findings, the final two recommendations reflect on how COVID-19 responses in rural areas might protect and further enhance women's collective influence.

\section{Key messages}

1. Contexts matter-understanding variation in village and district contexts (policy and other institutional arrangements, geographic conditions, and political, socio-cultural, and economic environments) is critical for addressing inequalities and improving gender inclusiveness.

- District and village environments interact to advance or constrain the ways women collectively influence decisionmaking, programs, funding allocations and ultimately experience development benefits.

- In the most conducive contexts-in which there is (emerging) political will and institutional support for gender inclusiveness-there are less constraints on women's collective influence and change is faster.

- In the most difficult contexts-in which social norms are highly restrictive for women, and there is little institutional or leadership support for gender inclusiveness-and in difficult sectors (such as reducing gender-based violence), deeper support is needed to bolster women's influence. Even then, in such contexts change is slower and incremental.

2. Village women can and do influence the implementation of the Village Law, often with structured support-but such influence varies with context constraints and opportunities, and can advance and regress over time at critical junctures.

- Institutional change (policies and regulations) to bolster gender inclusion are more effective if accompanied by resourced, concrete initiatives on the ground that embed gender inclusion in practice.

- Changes occur with structured support for (village) women, including the creation or strengthening of safe spaces and groups for women to interact, grow networks, skills, and knowledge, increasing their collective agency and ultimately their influence in public arenas.

- Women's influence in restrictive contexts tends to be via informal collective action pathways, particularly women's networked collective action, in which women garner support from other influential social and political actors to then together seek to influence change.

- Changes in gender-related social norms are slower compared with policy change, requiring deep, sustained investments that are best accompanied by practical initiatives, which build trust in villages and help to overcome context constraints.

- Critical junctures-e.g. elections, natural disasters, disease outbreaks - can regress or advance prior achievements in gender inclusion.

3. Working in partnership with civil society organisations (or other similar structures) that focus on gender inclusion and provide support to women's groups helps grow women's collective influence, and reduce rural gender inequities.

- Civil society organisations (CSOs) focused on improving gender inclusion tend to be experienced in facilitating the creation or strengthening of safe spaces, groups and networks for women to grow their knowledge, skills, and confidence as well as strategies for exercising influence and navigating context constraints.

- CSOs are highly adaptive-they can work across communities and with different policy and social actors to accommodate varied context features and to influence change in policy and on the ground.

- CSOs often have the networks, knowledge and experience to bridge different interests and groups, fill capacity and knowledge gaps among policy and other decision-makers on how to be gender inclusive and reduce inequities, and fill service gaps, the latter of which also serve as an entry point to build trust with leaders, women and communities.

4. Policies and regulations on gender inclusiveness are necessary for incentivising resistant actors-but alone are insufficient for on-the ground improvements.

- Policies and guidelines that create special forums for women or ensure generous women's representation in influential policy and decision-making arenas incentivise actors resistant to gender inclusion.

- Growing women's opportunities and capacities for networked collective action is also important for women to exercise influence, especially in restrictive contexts.

5. COVID-19 presents a critical juncture at which gender inclusion can advance or regress in rural areas.

- Tailor responses to accommodate context variation, build on achievements and manage risks for women. 


\section{Background}

Significant efforts have been undertaken by Indonesian women, civil society organisations (CSOs), other mass organisations, as well as various government ministries and subnational offices to reduce inequalities, including gender disparities, through policies, poverty alleviation programs, community driven development approaches and community organising initiatives. While notable achievements in gender inclusion and increasing women's influence have been made over the past two decades, improvements have been incremental and uneven, particularly rural areas.

Under Indonesia's decentralised governance structures, the Village Law introduced in 2014 devolves substantial decisionmaking and budget authority to some 75,000 villages. The new 2014 Village Law explicitly emphasises participatory community decision making, poverty reduction and gender equity, creating a framework for continued efforts to improve gender inclusion.

The Women's Collective Action and the Village Law study presented here aimed to:

- Investigate in depth, and at scale, the processes by which women have influenced the implementation of the Village Law and village development, with a particular focus on local (or grassroots) collective action by women,

- Understand how such influence varies across Indonesia,

- Identify what has constrained or enabled such influence, and

- Determine what has been the role for civil society organisations (CSOs) - as a structured, organised form of collective action that operates within but also beyond the village - in this process.

The study draws predominantly from mixed-methods qualitative research (backed up by some quantitative analysis) conducted in nine provinces, 12 districts, and 14 villages (see Figure 1). Each of the research areas has different livelihood options, geography and infrastructure, resource endowments, and population densities that shape policy, programs, and service design and delivery.

These contexts also have differing politicoeconomic interests and dynamics, regulatory and policy environments, influential state and nonstate actors, religious affiliations, social and customary norms, and dominant types of social networks.
Such features create enormous diversity in the subnational structures of authority, power and decision making across Indonesia that can form barriers to gender inclusion, narrowing the spaces for women to individually and collectively exercise voice, influence and agency. They can also however, create opportunities for change.

The study draws from mixed-methods qualitative research involving in-depth interviews (often repeated), life history interviews, and focus group discussions, involving more than 600 people, as well as observational data and informal conversations with many more women and community members. Data was collected through prolonged village stays and continued contact with participants over 2019. The study also draws from within case and comparative case analysis of CSO strategies, social networks, village and district contexts, and process tracing in the research sites (of women's influence on the Village Law), and some quantitative analysis on scale using databases collating data on women's groups and CSO activities in 27 provinces. ${ }^{i i}$

Fifteen CSOs and mass women's organisations (herein collectively referred to as CSOs), that have been engaged in community organising and supporting women, collaborated in the research. These organisations were partners in the Australia-Indonesia Partnership for Gender Equality and Women's Empowerment (MAMPU)-which also supported the research-and contributed to research planning, fieldwork facilitation, and iterative analysis. Participating national organisations and consortium networks include PEKKA, Institut KAPAL Perempuan, 'Aisyiyah, FPL, Migrant CARE, BaKTI, PERMAMPU, BITRA, and Yasanti. Subnational organisations include-YKPM, YABIKU, DAMAR Lampung, SPI Labuhan Batu, Perkumpulan Panca Karsa, and KPS2K.

Figure 1. Research Sites and CSO/Mass Women's Organisation Gender Inclusion Initiatives

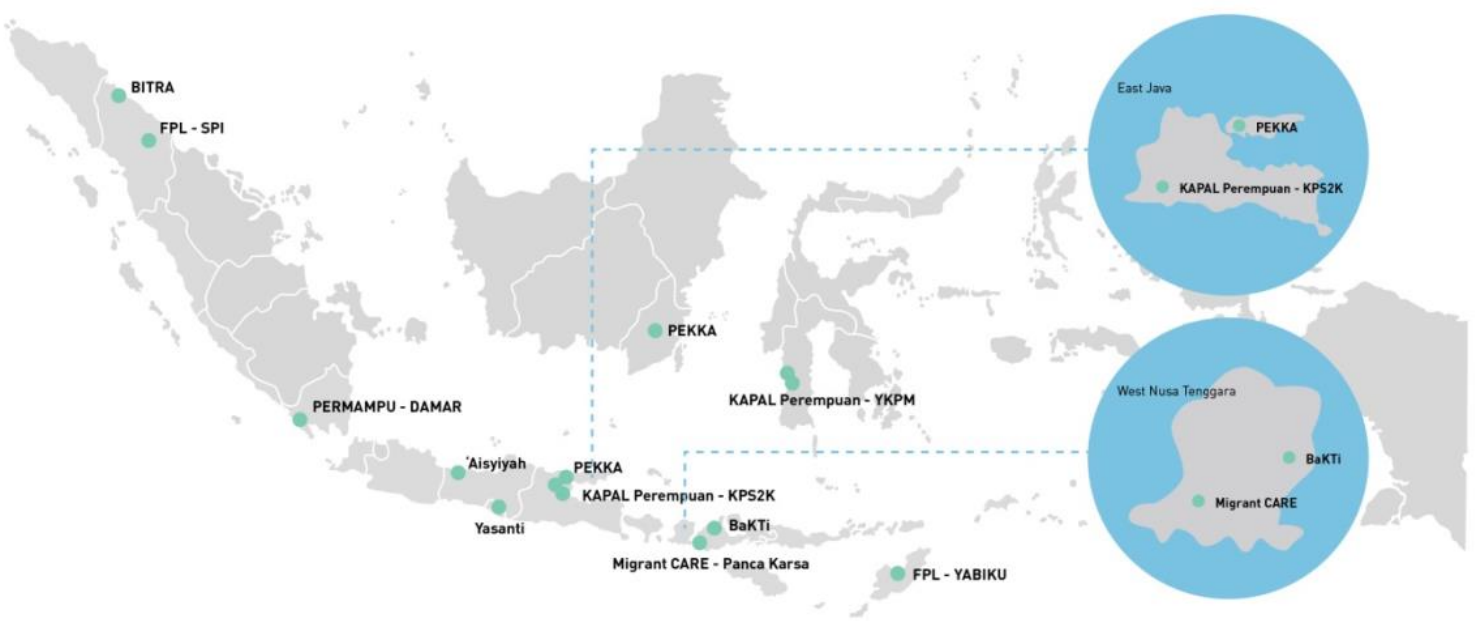


Other studies on the early implementation of the Village Law find that village women have tended to be less likely to influence the implementation of the Village Law at scale (see for example, the Sentinel Villages Study baseline results in Syukri et al. [2017, 2018] and Dharmawan et al. [2018] and other related research). However, these studies had few sites in the research sample where there were active civil society groups giving attention to Village Law implementation, and did not investigate in detail the mechanisms by which women have influenced Village Law implementation if and when this does occur.

To help fill this gap, this research uses a method of positive deviance for site selection by including sites in different regions across Indonesia where women's influence on Village Law implementation might have occurred to identify and analyse the mechanisms underpinning such influence. The research includes sites where CSOs were and were not operating to support village women. The research sites were selected to explore how village women might have influence on the implementation of the Village Law in rural Indonesia (via what pathways and mechanisms), if indeed they were able to do so, and to also establish if and how CSOs may have supported this process.

Working with and through grassroots groups: Given that the research draws from a sample of sites where MAMPU CSO Partners have sought to support village women (as well as 'control' sites where no such support has been provided to date), it is important to point out the common approach used by these Partner CSOS, that is, working with and through grassroots groups alongside broader advocacy to promote gender inclusion, with the goal of empowering women. This is a particular type of CSO intervention. Other CSOs may use a different approach and be less focused on the goal of gender inclusion and empowerment, which may have implications for women's collective action that are not explored here.

Broader applicability: The findings are nonetheless helpful for all audiences (not just CSOs) in understanding how grassroots women's collective action might be supported by group structures of different kinds that involve women, and how, or via what mechanisms, external actors might help bolster women's influence in villages and beyond. That is, even if not working with CSOs as partners in initiatives to bolster women's influence in governance, some of the features of the ways CSOs have supported women in the research sites to facilitate their agency certainly constitute important learning for other settings, actors and agencies concerned with gender-inclusive governance, structures of power, and socio-economic development.

This study captures the experiences of some of Indonesia's most vulnerable women: It is important to note that in their work, many of these organisations have endeavoured to access and support some of the most vulnerable women in Indonesia, who are often the poorest of the poor in villages that themselves tend to have high aggregate levels of poverty. This includes:

- Female-headed families,

- Victims and survivors of domestic and other forms of gender-based violence,

- Homeworkers, often with below-subsistence incomes,

- Women with limited livelihoods options seeking to overcome poverty through migrant work, who are vulnerable to exploitation by 'middle-men' that may use illicit channels to facilitate such work, and, among others,

- Those with little knowledge of issues such as reproductive health and nutrition or how to even access available social protection and poverty reduction assistance programs.

Many of the women in the study have experienced these multiple-dimensions of poverty or vulnerability all at once. These are the women that often fall through the cracks of poverty alleviation and social protection programs. They tend to have lower formal education levels, and may be significantly socio-economically, politically or even geographically isolated.

As such, in conducting research in many sites where research partner organisations have conducted activities (as well as sites where there are no CSOs present), this research has sought to capture in ethnographic detail the voices and experiences of some of the most vulnerable rural women in Indonesia. The research has focused on how these and other women take action to influence development decision making and wider structures of power, but also on the ways they build networks of influence with other actors and often then, together, collectively advocate for gender inclusive policies and practice. The study also captures the experiences of other women in the research sites who may still experience significant challenges but do not (or no longer) have the same heightened degree of vulnerability.

Multiple pathways: The study identifies the multiple pathways of action that rural women take in the research sites to exercise voice and agency, which has often, at least initially, been bolstered by CSO support for these village women, with each organisation having different approaches. While such support has been especially important in helping grow the agency and networks of more vulnerable women compared with those men and women more accustomed to exercising voice and influence, there may also be other pathways.

The findings are nonetheless more applicable for wider sets of actors, programs and organisations beyond CSOs, seeking to build trust with and provide support for rural village women and gender inclusive development and policy making.

We distinguish between when these actions seek to create positive changes for women in their everyday lives in general, and when this relates specifically to creating such changes via influence on governance processes and structures of power,

\section{Framework for Explaining Women's Influence}

We conceptualise women's collective action in this study as actions undertaken by collectivities, groups and networks, predominantly made up of women although often too with others, that seek to create positive changes in women's lives. 
which is important for understanding women's influence on Village Law implementation. The research analyses two forms of collective action:

1) Village women's grassroots collective action, and

2) Structured, organised forms of support for village women, including village-level initiatives and broader, organised CSO advocacy and action.

To understand women's collective action in different contexts-particularly the experiences of more vulnerable women-the analysis examines:

- The interaction between district and village socio-cultural, politico-economic, and institutional (policies, regulations, programs) settings and the ways such interactions constrain or advance gender-inclusive decision-making processes and structures of power-including how influential leaders shape these settings and variations across time and space (District and village contexts).

- The ways village women - individually and through new and existing collectivities (including informal spaces and organised groups and networks) - take action to exercise voice and influence in village and broader decision-making and structures of power (Pathways: Village women's experiences, and patterns in types and intensity of women's grassroots collective action).

- If and how village women's agency and collective action is supported by CSOs in different ways, each with different internal structures and forms of support (Pathways: CSO structures and support for women's grassroots groups and agency).

- The ways CSOs use planned and adaptive strategies to support women to navigate district and village context constraints (Pathways: Strategies).

The analysis then determines how such action shapes institutional rules (e.g. regulations), socio-cultural gender norms, and Village Fund (Dana Desa) allocations under the Village Law (See Figure 2).

Figure 2. Contexts and Pathways: Women's Influence on Village Law Implementation

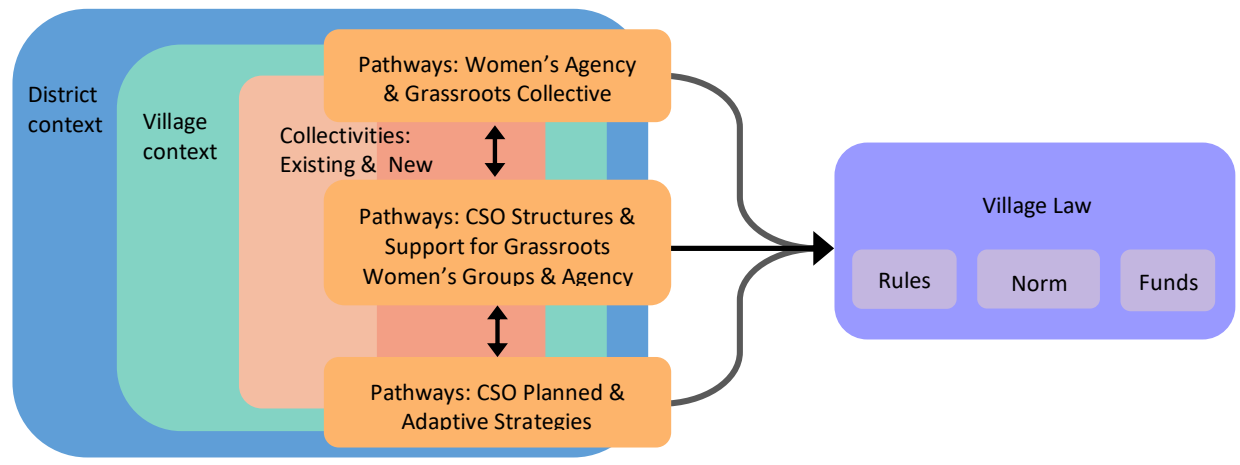

\section{Key findings: Variation in District and Village Contexts}

1. Gender-inclusiveness varies significantly across district and village contexts, creating differential constraints and opportunities for women to exercise voice and influence.

Contexts interact with and shape the pathways for women to influence village development and wider gender-inclusiveness in Indonesian society. A range of factors constrain and create opportunities for women's influence in rural Indonesia:

- Different budget priorities and institutional rules (policies and regulations)-more gender inclusive regulations and guidelines are important for incentivising actors resistant to gender inclusiveness.

- The political economy in districts and villages-power is both visible and hidden in different contexts; the way power is structured and exercised can promote or restrict gender inclusiveness. Some regions display a high degree of plurality in terms of the scale and diversity of the political and social institutions, organisations, groups and leadership that have socio-political influence. Others are narrower - there are fewer influential actors, organisations and institutions, and more closely aligned interests which may or may not be committed to women's inclusion in decision making and wider gender equality.

- Existing political will of government and social leaders to support empowerment agendas-leaders can speed up and limit gender inclusiveness through public discourse, program priorities, and policy design.

- The degree of alignment between politically-determined development policy priorities and key concerns, gaps and needs identified by women and CSOs - the wider the gap, the more difficult it is for women to have influence and for their voices to be heard, but this can change over time.

- The types and nature of networks between actorsbuilding stronger, deeper networks between village women and authoritative and influential village, district (and provincial/national) leaders supportive of women's empowerment creates a greater likelihood for networked collective action to result in gender-inclusive institutions, programs, and ultimately structures of power and decisionmaking.

- Informal socio-cultural norms-socio-cultural gender norms are a significant and often hidden barrier for women to exercise voice and influence, particularly in public life and development decision-making. Changing such norms can and does happen through women's networked collective action, but change is slower and more incremental, often lagging behind policy and program changes 
2. Changing such norms can and does happen through women's networked collective action, but change is slower and more incremental, often lagging behind policy and program changes.

Districts in some cases constitute a more conducive environment for gender inclusiveness, but this does not always correspond with village dynamics. Likewise, villages can be innovative even in light of district institutional and political environments that by design or default are restrictive for women's empowerment. Both realms, tend to interact to produce differential conditions for women's collective action and influence.

Context dynamics affect the everyday challenges women face and the extent they can individually or collectively exercise influence in public and often private realms. They also shape the forms of women's grassroots collective action, the nature and scope of on-the-ground initiatives to support these women, and the different CSO approaches to support village women to navigate contexts and more broadly to advocate for policy change. This has implications for if and how women can influence village governance, so as to contribute to their efforts to improve their wellbeing.

The analysis presents four broad categories of contexts, which are more or less conducive to women's influence and gender inclusiveness and reflect both interacting district-village dynamics as well as indicators of 'difficulty' for introducing or strengthening gender inclusion (see Figure 3). Based on onset conditions before CSOs - with the support of MAMPU-sought to support village women through empowerment initiatives, many research sites displayed highly to moderately difficult context features.

Highly difficult contexts for broader women's influence in village and district governance, and more explicitly on the implementation of the Village Law, are those in which there are weak, if any policies, regulations and programs that encourage women's participation, and little political willingness among state and social leaders to support such an agenda at both district and village levels.

They also display strong social norms that limit women's influence in public life and cultural taboos on discussing issues affecting women-e.g. gender-based violence and reproductive health. Power tends to be concentrated among a small set of authority figures (both state and social leaders) who may be resistant to empowerment agendas, particularly those that are perceived to challenge status quo authority structures. There tend to be few groups in which women can comfortably and collectively act, or if these groups exist, membership diversity is limited.

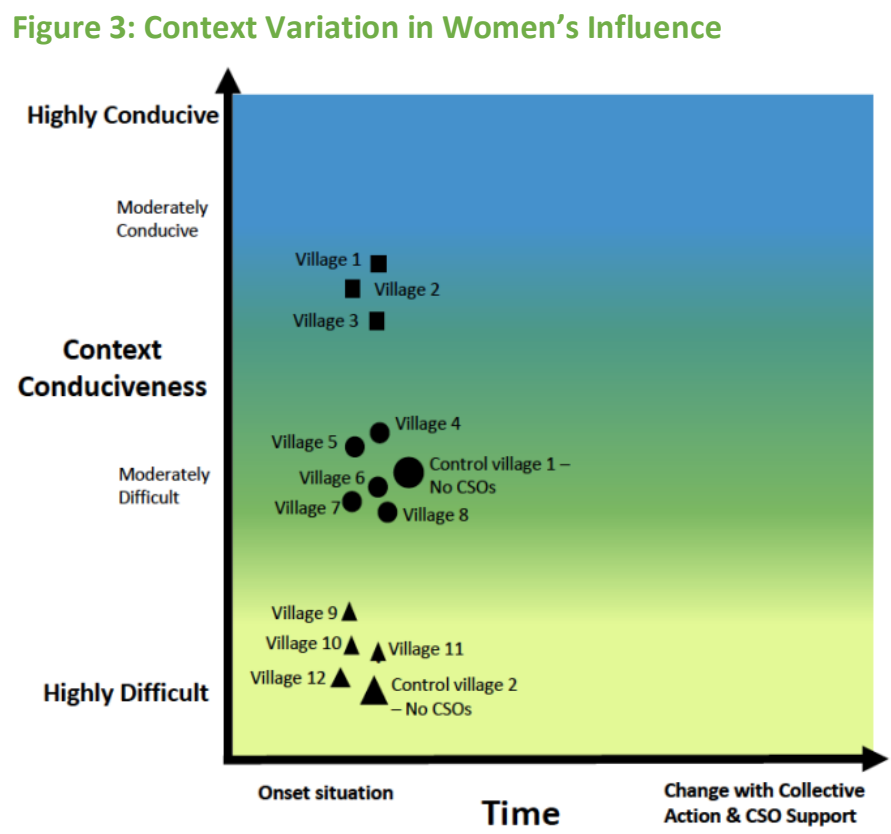

Highly conducive contexts, display a greater degree of plurality of social and political authority figures at both district and village levels and indicators of policy and leadership support for empowerment, including progress towards institutional change. There often is a stronger representation of women in decision-making positions (particularly at the district level), and stronger, more diverse groups and forums for women's collective action and decision making. There also tends to be less resistance to gender inclusiveness, particularly when priority issues for village women and CSO advocacy agendas are aligned with political priorities.

Moderately difficult contexts display many of the features of highly difficult contexts, but there are indicators of changes occurring (or opportunities for change) at either district or village levels.

Moderately conducive contexts have embarked on a path of supporting gender inclusion at either district or village levels, usually supported by a high degree of political willingness, but may not have fully developed supporting institutional arrangements or the issues being tackled traverse more sensitive social norms.

\section{Key findings: Pathways-Forms, Intensity and Patterns of Women's Collective Action}

\section{Women's collective action is both formal and informal in type in rural Indonesia.}

For women in rural areas who are deeply embedded in the social networks that shape village life, and for more vulnerable women, collective action is unlikely to involve 'collective protest on the streets' to often unknown authorities with significant power. Rather, it involves exercising voice and agency often through informal processes involving more informal forms of influence through connecting to influential social and political figures, groups and organisations, in which women and these actors then together influence structures of power and decision making.

Analysis finds the forms of women's collective action in rural Indonesia are of different types situated on what is more or less a continuum (with some overlap between types) of more informal forms of influence through these interpersonal networks developed with authoritative government and social leaders, to participating in formal processes of decision making in organisations, institutions, and forums (see Figure 4 below). 
Connecting more vulnerable women into the structures of power and decision-making has tended to involve establishing networks and the interrelated dimensions of slowly and incrementally building confidence, skills, capacities and knowledge for exercising voice and influence. Much of the action then takes place through these networks and involves a broader set of actors collectively advocating for change.
Many of the forms of collective action identified in the research were interrelated, sometimes sequential, sometimes overlapping and often mutually strengthening in the processes and trajectories of change mapped in villages, especially those that led to women having greater influence on the structures of power and decision making.

\section{The patterns of the forms and intensity of women's collective action vary with context constraints.}

The intensity and forms of village women's collective action, bolstered by the support of CSOs, vary across highly difficult and conducive contexts. In Figure 4, darker colours indicate the intensity of each form of women's collective action observed in the research sites.

In highly difficult contexts most forms of collective action were informal and involved interpersonal networks developed and strengthened over time between village women and other influential government and non-government 'champions' of gender inclusiveness. Through these networks, women sought to build trust with and persuade sometimes resistant village decision makers of the benefits of inclusive village development. One exception was village women and CSOs working together with village governments to design and enact village regulations on issues important to women.

In moderately difficult contexts, forms of collective action were more varied across formal and informal types, and of greater intensity, given the signals of opportunities for change through joint action. Over time, more institutionalised forms of gender representation and collective action became increasingly prevalent through rules (policies and regulations), forums and programs, which evolved to be more gender inclusive, while informal action continued.

In more conducive contexts, formal, institutionalised forms of collective action were increasingly prevalent compared with other places, including women's (collective) participation in village government planning and decision-making forums (such as MusDes and/ or Musrenbangdes), in similar district government decision-making forums, or by their involvement in formulating the content of new regulations, policies and programs. It also includes participating in elections as candidates and taking on other leadership. Informal forms of collective action were important in conducive contexts, particularly for vulnerable women, but women did not need to rely as extensively on networks to exercise influence.

\section{Networked collective action}

Across the research sites, particularly in the most difficult contexts (see Figure 4), the study observed a range of collective action processes driven by women's efforts to establish relationships and networks of trust with authoritative actors that have influence over governance processes and social norms. This study refers to these processes as women's networked collective action. That is, the efforts of women and other actors to, collectively endeavour to influence governance, development, policy programs and structures of power to be more gender inclusive. Networked collective action involved women building or strengthening networks of trust with other women (through groups and informal spaces), and with other community members, especially authoritative actors often through engagement in everyday settings.

Figure 4: Patterns of Women's Collective Action

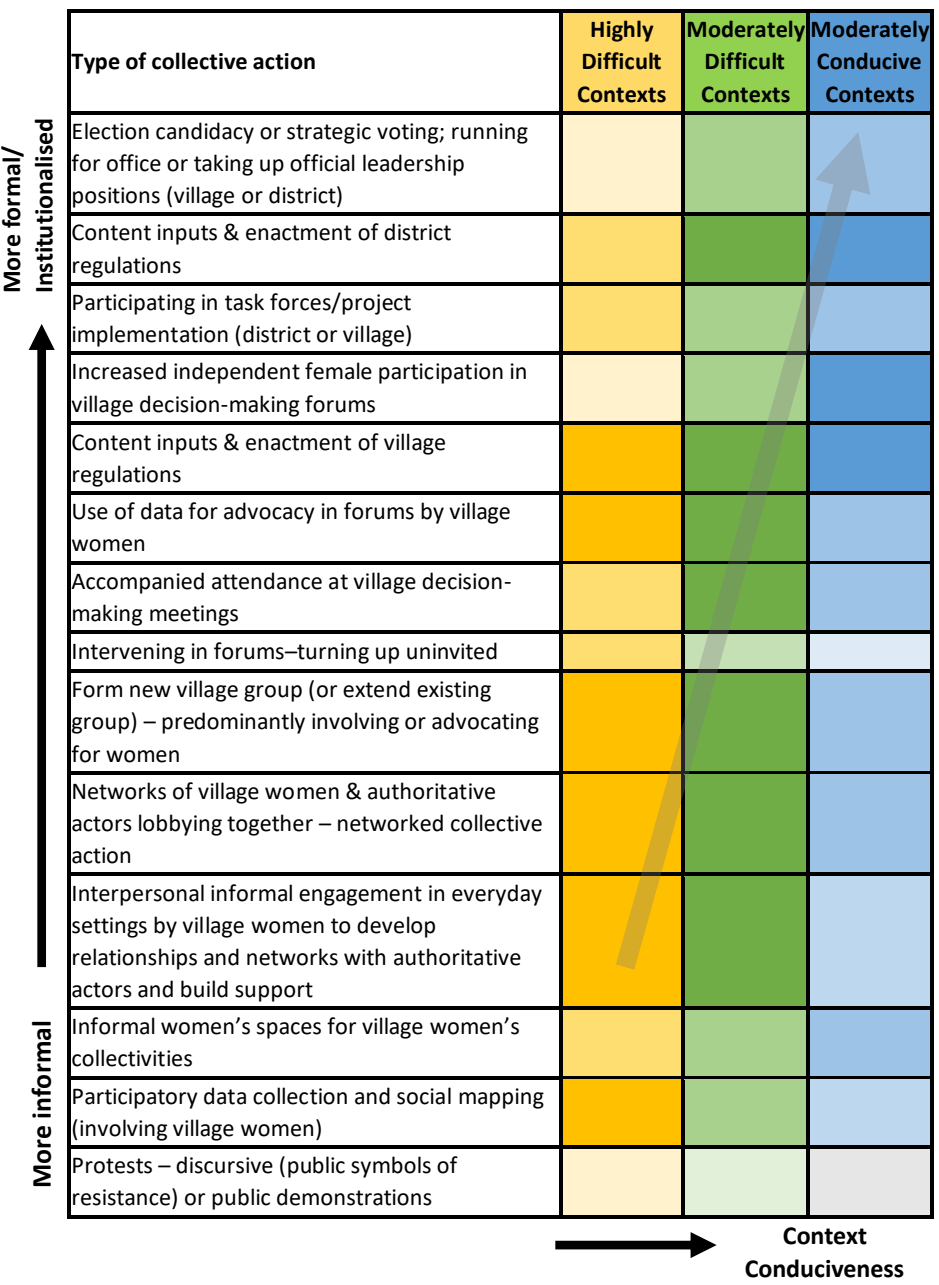

It then involved village women leveraging their newly established or existing networks to garner support for their endeavours. This then created multiple sources of pressure on authoritative actors and ultimately decision-making forums and power structures, so as to influence outcomes. Such processes were also helpful for overcoming challenges, particularly resistance among authoritative and influential figures to gender inclusiveness. Women's informal spaces and more formal groups bolstered this process by extending networks, providing a new arena in which to build individual and collective agency through shared knowledge, skills and resources, providing mutual support and a source of protection, and fostering a sense of solidarity and collective agency. 
5. Village women can and do influence the implementation of the Village Law, particularly with structured support - but influence varies with context constraints and opportunities.

The study establishes, that indeed, across the research sites throughout nine provinces, village women were able to grow their power and collective influence on the implementation of the Village Law and make significant contributions to village governance. For vulnerable rural women, this was particularly the case when they were supported by CSOs using a variety of planned and adaptive strategies, and wider advocacy. However, with confidence and networks such action then took on a life of its own.

Figure 5: Women's Collective Action and Impacts on the Implementation of the Village Law

\begin{tabular}{|c|c|c|c|c|c|c|c|c|c|}
\hline \multirow[b]{2}{*}{ Context } & \multirow[b]{2}{*}{ CSO } & \multirow[b]{2}{*}{ Sectoral focus } & \multicolumn{5}{|c|}{ Changes over time in village contexts and Village Law implementation } & \multicolumn{2}{|c|}{$\begin{array}{c}\text { District institutional } \\
\text { change over time }\end{array}$} \\
\hline & & & $\begin{array}{c}\text { Women's } \\
\text { participation in } \\
\text { forums }\end{array}$ & $\begin{array}{c}\text { More women } \\
\text { in leadership } \\
\text { positions }\end{array}$ & $\begin{array}{l}\text { Social } \\
\text { norms }\end{array}$ & $\begin{array}{l}\text { Rules \& } \\
\text { policies }\end{array}$ & Village fund $\$$ & $\begin{array}{c}\text { District } \\
\text { policies \& } \\
\text { regulations }\end{array}$ & $\begin{array}{c}\text { District/ } \\
\text { provincial } \\
\text { funds }\end{array}$ \\
\hline \multirow{4}{*}{$\begin{array}{l}\text { Conducive } \\
\text { contexts }\end{array}$} & Village 1- DAMAR \& FAKTA, & Women's Health \& Nutrition, \& & \multirow{2}{*}{$\checkmark \checkmark$} & \multirow{2}{*}{ Already } & \multirow{2}{*}{$\checkmark$} & \multirow{2}{*}{$\checkmark$} & \multirow{2}{*}{$\checkmark$} & \multirow{2}{*}{$\checkmark \checkmark$} & \multirow{3}{*}{$\checkmark$} \\
\hline & PERMAMPU Consortium & Reducing Violence Against Women & & & & & & & \\
\hline & Village 2 - Yasanti & Better work conditions & $\checkmark \checkmark$ & & N/A* & $\checkmark$ & $\checkmark$ & $\checkmark$ & \\
\hline & Village 3 - PEKKA & Social Protection & $\checkmark \checkmark$ & $\checkmark$ & $\checkmark \checkmark$ & $\checkmark$ & $\checkmark$ (short-term) & $\checkmark \checkmark$ & $\checkmark$ \\
\hline \multirow{6}{*}{$\begin{array}{l}\text { Moderatel } \\
\text { y difficult } \\
\text { contexts }\end{array}$} & Village 4 - KAPAL Perempuan \& KP2SK & Social Protection & $\checkmark \checkmark$ & & $\checkmark$ & & $\checkmark \checkmark$ & $\checkmark$ & $\checkmark \checkmark$ \\
\hline & Village 5 - 'Aisyiyah & Women's Health \& Nutrition & $\checkmark \checkmark$ & $\checkmark$ & $\checkmark$ & $\checkmark \checkmark$ & $\checkmark \checkmark$ & $\checkmark \checkmark$ & \multirow{3}{*}{$\checkmark \checkmark$} \\
\hline & Village 6 - BaKTI & Reducing Violence Against Women & $\checkmark$ & & $\checkmark$ & $\checkmark \checkmark$ & $\checkmark \checkmark$ & $\checkmark \checkmark$ & \\
\hline & Village 7 - Migrant CARE \& Panca Karsa & Migrant Workers & $\checkmark$ & & $\checkmark$ & $\checkmark \checkmark$ & $\checkmark$ & $\checkmark$ & \\
\hline & Village 8 - BITRA & Better work conditions & $\checkmark \checkmark$ & $\checkmark$ & $N / A^{*}$ & (Draft) & & $\checkmark \checkmark$ & $\checkmark$ \\
\hline & $\begin{array}{l}\text { CONTROL VILLAGE } 2 \text { - NO CSO } \\
\text { Presence }\end{array}$ & N/A & $\begin{array}{l}\checkmark \text { (very } \\
\text { limited) }\end{array}$ & $\checkmark$ & & & & N/A & N/A \\
\hline \multirow{5}{*}{$\begin{array}{l}\text { Highly } \\
\text { Difficult } \\
\text { contexts }\end{array}$} & Village 9 - KAPAL Perempuan \& YKPM & Social Protection & $\checkmark \checkmark$ & $\checkmark$ & $\checkmark$ & & $\checkmark$ (short-term) & $\checkmark \checkmark$ & $\checkmark$ \\
\hline & Village 10 - FPL \& YABIKU & Reducing Violence Against Women & $\checkmark \checkmark$ & & $\checkmark$ & $\checkmark$ (Draft) & $\checkmark$ & $\checkmark$ & $\checkmark \checkmark$ \\
\hline & Village $11-F P L \&$ SPI & Reducing Violence Against Women & $\checkmark \checkmark$ & & $\begin{array}{c}\checkmark \\
\text { (slowly) }\end{array}$ & $\checkmark \checkmark$ & $\checkmark$ (not released) & \multirow[t]{2}{*}{$\checkmark$} & \\
\hline & Village 12 - PEKKA & Social Protection & $\checkmark$ (partly) & & $\checkmark$ & $\checkmark \checkmark$ & $\checkmark$ (Small amount) & & \\
\hline & $\begin{array}{l}\text { CONTROL VILLAGE } 1 \text { - NO CSO } \\
\text { Presence }\end{array}$ & N/A & $\begin{array}{l}\checkmark \text { (very } \\
\text { limited) }\end{array}$ & & & & $\checkmark$ & N/A & N/A \\
\hline
\end{tabular}

N/A*. In this site we investigated women's collective action and CSO gender inclusion and empowerment approaches but did not undertake deep village analysis of social norms.

Examples of increased influence include new rules and policies (at both village and district levels) such as perdes (Village Regulations), perda/perbup (Regional Regulations/ District Head Regulations), and technical guidelines prioritising women's needs and sensitivity to gender inequities. In some places, special women's development planning meetings at village/district levels (Musrenbangdes/ Musrenbangda) were held or women were encouraged to attend village/district decision-making forums. Examples of increased influence also include Village Fund (Dana Desa) and sometimes district/provincial allocations for programs benefiting women, and some influence on gendered social norms in villages (albeit slowly) through initiatives implemented with the support of the village. Such influence was less evident in control sites, and overall change tended to be slower and incremental in the most difficult contexts (Figure 5 above).

It was also evident that in places where women had influence on Village Law implementation (albeit to varied degrees), there was significant diversity in the range of initiatives that women introduced, which included but went beyond infrastructure and economic development. This ranged from new projects to establish clean water, sanitation, and solar- powered electricity facilities, to creating village-funded service posts that serve as a safe space for women to report and receive assistance in cases of gender-based violence, as well as safehouses for these women and their children. Women also gained village support and funding for nutritional gardens, reproductive health services, village ambulance services, Early Childhood Education facilities, integrated health post facilities, women's care posts, paralegal services, as well as support for informal sector workers' groups, citizen documentation and religious marriage certification.

In multiple villages, women also successfully proposed villageowned enterprises (BUMDes) to help diversify livelihoods options for women (and the wider community). In one region a one-stop service provision centre was established to help migrant workers access and follow legal administrative processes to work overseas, and to train returned migrant workers and their families on how to utilise remittances for sustained livelihoods.

Overall, the diversified village development outcomes identified in the study that resulted from women's influence on Village Law implementation included village economic and social policies and projects, as well support for training, skills 
development and information dissemination, service delivery and other initiatives. To institute these initiatives, in many cases women also initiated and led new multi-stakeholder forums, task forces, and other mechanisms to tackle particular issues, and garnered the support of other stakeholders to participate in these forums.

\section{Key findings: Pathways of Influence-How CSOs help improve gender inclusion}

6. CSO grassroots support for vulnerable and often marginalised rural village women helps create pathways for their influence and inclusion in village development, particularly in difficult and moderately difficult contexts.

Women's essential capacity and readiness for acting individually and collectively form the basis for fostering women's voice, influence and empowerment. In turn, this may bring about longer-term changes in women's own welfare in terms of women's access to public services and programs that improve their livelihoods, and the participation of women in governance processes and their influence over wider social and political power structures.

What is clear from the analysis is that supporting (or strengthening) the creation of safe, informal spaces and more formal, resourced, inclusive and organised groups for women, helped strengthen and grow women's social capital and their individual and collective agency over time. Given many longstanding practices of exclusion, particularly in the public sphere, participation in the types of groups examined in this study helped strengthen village women's power within, that being their sense of self-worth and confidence, the power of women to act in public realms and their power with other women (and broader networks) to engage in collective action and exercise greater influence and (albeit not exclusive) power over structures of decision making and village development outcomes.

This occurred through multiple interacting and overlapping processes generated from group participation, such as:

- Strengthening and diversifying supporting networks and friendships with other women,

- Fostering a sense of solidarity and understanding of the issues many women face,

- Growing and sharing skills, access to resources, and knowledge,

- Strengthening organisational and leadership skills and experience,

- Providing a safe space and a source of protection,

- Building confidence and mutual support to overcome barriers and obstacles,

- Developing women's collective strength to have wider influence, and, among others,

- Providing an organised and recognised platform for: driving women's collective action of multiple forms, and for connecting to and collaborating with other actors and groups in villages and beyond to participate in women's wider networked collective action.

CSOs trusted by village women helped facilitate such groups and spaces, and provided additional support for more vulnerable women to navigate barriers to their inclusion in development decision-making. Most often, the CSOs in this study supported village women to establish new women's groups, although in some cases, particularly in difficult contexts, CSOs supported existing women's groups, working with them to broaden the group agenda and diversity of membership. In a number of cases, CSOs supported village women to establish mixed gender multi-stakeholder groups to support village development, but for women these were best accompanied by other formal and informal women's spaces in which they felt safe. Without such spaces and support, particularly in the most difficult contexts and for the most vulnerable and marginalised women, the barriers to inclusion were so great that it was difficult for village women to embark on a journey of trying to 'suddenly' influence power dynamics, particularly in the face of both hidden and more explicit long-standing practices of exclusion. CSOs became one among the constellation of supporting actors in women's networked collective action.

Drawing on ethnographic detail, analysis illustrates how many women throughout the research sites described journeys of surprise and bewilderment as their gender awareness grew, and then often confusion when they encountered fierce resistance from friends and family with whom they shared their experiences. They explained the fear, stigma and threats they experienced both within households and in community settings as they sought to get more involved in village development and public life. They often faced resistance from village authority figures with the power to exclude women from 'everyday' social, economic and other networks and opportunities on which they rely to meet basic needs, often in situations of extreme impoverishment.

Yet, women's journeys were filled with accounts of perseverance, bravery and taking risks in promoting change and driving collective action, bolstered by group support. They encountered setbacks over time, which many were able to overcome-sometimes alone, sometimes with CSO supportindicating that village women's efforts to improve gender inclusion require time and continued support as journeys are not always positively and upwardly linear.

Women also described the personal benefits-social, economic, skills, networks, knowledge, support-of joining women's groups for the first time and how this helped them forge new pathways. Across the 27 provinces where MAMPU CSO Partners have worked, by June 2020, nearly 3500 groups were established with MAMPU program support, involving some 73,000 women and 3000 men.

The study also found there were cohort experiences of those village women who emerged as key leaders and mobilisers in driving women's collective action, especially early on. Some had prior life experience in organising (as members of groups, including state-corporatist women's groups), or experience in public-facing roles through their income-generation activities or education, and/or learned to leverage social or family networks for support. These women were better equipped to take on leadership roles to mobilise and drive collective action when the opportunity arose, although were not always aware nor confident that they had such potential-some had not dreamed they could take on such leadership roles. 
Yet, such a background was not essential: others, particularly those from more vulnerable groups, were also able to lead action with encouragement and group support. Understanding these cohort experiences among leaders is helpful for

7. CSO structures and approaches to support to village CSOs have different organisational structures, networks, and length of establishment, work at different scales, focus on different issues, and work in different regions (with varied context difficulties for promoting gender inclusion). Many CSOs and mass women's organisations examined in this study consisted of either national (or large regional) networks of organisations (some network member organisations also have their own partner organisations), national-subnational organisational partnerships supporting women in particular regions, or organisations connecting to communities with branch structures, with growing scale over time. They also connect to communities through different combinations of staff, paid and unpaid community organisers, village cadres, which can change over time. These dimensions have implications for:

- Choices on targets, resourcing decisions and the nature and depth of impacts at different scales.

- How CSOs collaborate with development partners on new initiatives and that external support for CSOs is not amenable to a 'one-size-fits-all' approach.

Analysis found CSO planning choices were made to have the greatest impacts within the bounds of their organisational structures/networks and were often dependent on human/financial resource availability, their sectoral focus and whether this might traverse cultural taboos. In addition, the degree to which CSOs already had established district or villagelevel relationships, context dynamics, and the nature of the activity at hand also had implications for their choices and approach to establishing, extending or strengthening their connections to and support for women at the grassroots. Some CSO organisational structures and approaches were comprised of a number of the following features, with each having advantages and trade-offs:

- Network consortiums have wide reach and can operate at scale (some consortium member organisations also have their own partnerships with other organisations), but often lack sufficient resources at the national level for monitoring and determining who might emerge as agents of change during new initiatives to support village women, particularly early on, but also over time.

women present different opportunities and trade-offs. providing support for these partners that also vary in their approaches, levels of experience, and length of establishment.

- National organisations with sub-national partnerships tend to have reach in particular regions and support specific partners over time in localities, and depending on national resource availability, work at small or medium scales on resource-specific timeframes.

- National organisations with branch structures are able to establish long-term support to women in localities, but this involves time and significant resources to establish and build support.

- Those working with cadre structures (in some cases national, in others local organisations) are often able to build local trust and work quickly in new villages (often fewer in number but more intensively), but support to cadres is resource intensive for staff and village cadres can also be unwittingly affected by village politics-new leaders can sideline cadres associated with rivals.

- Those with community organising structures in which CSO staff/field officers live in or nearby villages can provide deep support to village women-and to cadres where applicable-in difficult contexts to navigate hidden and visible barriers to inclusion, but work intensively in fewer regions with the resources available.

- Most CSOs working in difficult contexts need to supplement village government capacity and village service gaps-leaders may be willing to engage with initiatives to bolster inclusion but do not know how to go about it nor how to design village regulations or appropriately allocate funding to support women's self-identified priorities.

- 'Do it for them' approaches sped up progress in the shortterm. 'Do it with them' approaches took longer, but knowledge was shared and skills transferred to both village women and authority figures, having implications for longer-term sustainability when CSO support receded.

\section{Tailored strategies to support village women are effective in the most difficult contexts but involve deep, sustained human}

and financial investments over longer time horizons

Analysis highlights that CSOs have also supported village women by using strategic and adaptive approaches to undertake advocacy, and to help village women navigate context constraints. For example, supporting women in participatory data collection on village women and their self-identified needs, as well as social network mapping, is helpful for both village women and for CSOs themselves to identify, build connections with and leverage the support of 'champions' to lobby others with significant power in villages and districts. Such data collection is also an important step for CSOs in accessing new villages.

Other approaches and strategies were also used by CSOs to help facilitate village women to garner the support of what commonly might constitute resistant authorities to gender inclusiveness and empowerment agendas. Learning from the experiences of village women and CSOs across the study, in the most difficult contexts, successful support for village women to influence village development entailed (Figure 6). 
Focus on fewer villages but heavier investments, with support based on network and social mapping and data collection on needs with community members.

Carefully sequenced village access, entry and activities in village and leveraging social networks and 'champions' for support, developing relationships with local and district elites for support while building trust with communities.

Embedded CSO staff in villages (live in or nearby for frequent engagement) to support women and build trust.

Accompanying women to any decision-making forums or encounters with village power structures.

Facilitating extended networks and 'networked collective action' by connecting village women (organised in women's formal and informal groups) with influential actors across policy, social and regulatory fields.

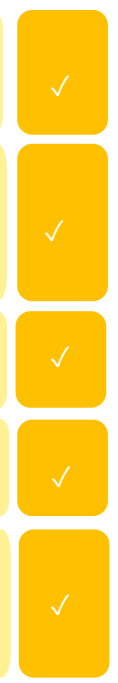

Strengthening women's practical skills- economic, livelihood, parenting, health, and literacy skills-and intrinsic skills, wider knowledge, gender awareness, and understanding of government administrative processes through groups.

Filling gaps in knowledge (e.g. regulatory design) and essential services - e.g. healthcare, citizen legibility, safe migration, safe houses.

Ensuring some women's group activities have an economic focus, or are framed as such, is helpful (but not necessarily sufficient) for women's participation.

If focused on social norms, accompany this focus with other practical development activities.

Planning for transitions such as changes in leadership, including the implications of any support for women's groups from prior leaders.

\section{Key findings: Pathways of Influence-Village Law and Empowerment Outcomes}

9. Rules are an important, necessary incentive for resistant actors to support inclusion, but rules alone do not generate outcomes.

Under democratisation and decentralisation, significant efforts have been made to grow democratic decision making and to include communities in processes to determine development priorities - the introduction of the Village Law is another step in this process. However, there are often hidden barriers to gender inclusion that are shaped by both social norms on gender roles and the way structures of authority and power are configured (and historically embedded). These then privilege actors from particular networks, families, and other groups who have long been involved in political and policy decision making or have exercised influence in economic or social realms.

Analysis found that important in the process of improving gender inclusiveness was introducing regulatory reforms (through village and district regulations, instructions and policies) and technical implementation guidance so as to institutionalise the inclusion of women in decision-making processes and fund allocations. Village and District Heads, subnational governments, and other leaders responded to regulations, 'guidance' and lists of priorities for spending from central ministries and districts.

Rules alone did not assure women's influence. Yet, rules did create incentives over longer time frames for resistant leaders and decision-makers to involve women in decisionmaking and to prioritise funding allocations for women,

10. CSO support for village women and grassroots networked collective action had wider gender inclusion effects - changing contexts and institutionalising gender inclusiveness over time.

Across the research sites in which CSOs of different types, structures and approaches sought to support village women and women undertook different forms of collective action, broader changes in gender inclusion were evident (See Figure 7). This was the case even in places more resistant to gender inclusion and empowerment agendas, especially when compared with control sites where no such support and minimal collective action existed. particularly in the absence of village-level facilitation to bolster community participation in planning. Women being supported to overcome hidden and explicit barriers to exercising power was also an important catalyst for outcomes. Many examples were evident of how policies determined at multiple levels, including by villages, bolstered inclusiveness. To note a few:

- Creating forums, such as village and district development planning forums (Musrenbangdes and Musrenbangda) designated for women, structuring mixed forums to have generous representation of women, and ensuring women's voices are substantively taken into account (not just an administrative step),

- Ensuring women were specifically invited and welcomed (not nominally including one group representative in decisionmaking meetings).

- Earmarking minimum funds for initiatives that were selfdetermined priorities for and driven by women-including

- Officially and formally recognising women's groups in regulatory arrangements (e.g. perdes, perda, perbup) such as many different women's unions (female-headed families unions, homeworkers unions, village women's unions), and others such as mixed gender constituent groups, migrant worker support groups, and task forces. allocating specified funding in perdes/perda.
Women's collective action not only saw greater women's influence over village development and budgets allocated to support activities proposed by women's groups, but also the increasing institutionalisation of gender inclusive decisionmaking. That is, contexts became more conducive to women's influence and participation in development decision making and public life over time. This not only resulted from the efforts of various types of women's groups, but also resulted 
from village women and often CSOs working closely with government and other influential actors to develop gender inclusive regulatory frameworks, policies and processes. In most cases, in the intervention sites, even in places more resistant to gender inclusion and empowerment agendas, changes were evident in the regulatory frameworks in districts and villages, which have implications for some if not all dimensions of gender roles, rights, responsibilities and representation (or the $4 \mathrm{Rs}$ ).

Analysis revealed that improving gender inclusiveness, particularly for the most vulnerable women, entailed the dual imperatives of undertaking both advocacy and concrete initiatives at village and district levels, which was also augmented by national level partnerships with government and mass organisations.

Subnationally, in conducive contexts, changes were apparent (but not necessarily embedded) after 3-4 years of support for village women, depending on the sectoral focus and scale of the endeavour.

Larger scale initiatives, for example those focused on livelihoods or social protection for the poorest women, required longer for building support. Here, introducing regulatory reforms, program or service roll out, evaluation and fine-tuning of pilots and implementation at scale, took between 4-6 years.

In the most difficult contexts, particularly at the village level, even small-scale initiatives required longer and deeper investments (over 6-10 years). Sequenced villagelevel change in one or two aspects may be evident after 3-4 years of such investments but much longer time frames are needed for policy and institutional change to take effect and become embedded in contexts. This was particularly the case for focus issues that traverse cultural taboos, or cross-cutting initiatives that interact with or seek to deepen intractable power structures that exclude women.

\section{Figure 7: Empowerment Effects: Influencing Context}

\section{Constraints}

11. A sectoral focus is a key factor affecting the speed of change and advancement of gender inclusion — focus on changing social norms alone is likely to be highly resisted.

Initiatives that traverse cultural taboos such as domestic violence and women's reproductive health, require significant time frames and tailored strategies of support regardless of the context.

Analysis clearly finds that efforts to change social norms and attitudes towards women is slower and incremental, particularly in places where social conventions are significantly different to the values espoused in empowerment agendas. This includes places where, over time, village decisions are made by the same sets of influential actors, women rarely occupy influential leadership positions, there are few norms that support gender-inclusive decision making in public forums, and social norms often confine women to domestic roles or at best to both domestic and income-generating roles.

In the study villages, change tended to occur when a focus on social norms was accompanied by other broader development activities in villages. Embarking on an agenda of tackling social norms alone is likely be strongly resisted on entry into village environments when leaders are suspicious of such agendas. Small changes in targeted villages may be evident in 4-5 years with deep support, but for initiatives at scale, district-wide institutional change may take 5-10 years with the collective involvement of women's groups, multiple CSOs, government champions and other organisations.

\section{Journeys to gender inclusiveness are not necessarily upwardly linear and progressive, they can advance and regress over time at critical junctures.}

Women's collective action and influence over governance and broader structures of social and political power can be bolstered or constrained by ruptures in the external politicoeconomic environment at critical junctures - their journeys are not always upwardly linear and progressive. Such ruptures can shut down or open up spaces to advance gender inclusion, and can also reverse some of the gains made.

Changes in village and district leadership during elections, or the overwhelming disruptions that occur with natural disasters, are just two examples. The study found that even when the tenets of gender inclusion begin to surface over the short term of a few years, it cannot be assumed that they are sufficiently strong to resist these ruptures.

New leaders may seek to shut down women's participation in decision-making forums or close off funding for initiatives that received prior support, particularly in less conducive contexts. Equally, following the earthquake disaster in Lombok and in the recent COVID-19 pandemic, in regions where prior community organising initiatives to empower women had taken root, women in these villages were the first to move to 
respond to these disasters, taking on leadership positions and tailoring recovery efforts to community needs.

The findings from a selection of research regions presented in Figure 8 shows the diversity of progress over time. In some places at critical political moments village-level progress on gender-inclusiveness regressed while the district environment continued on the path to greater conduciveness.
It is evident too in the analysis that changes in social norms tend to lag behind institutional changes (see Figure 8 , Villages 1 and 10). Progress made to influence village and district contexts does not always move at the same speed or in the same direction (Figure 8, Villages 9 and 4) due to context dynamics, particularly at critical junctures, even if similar degrees of support and types of initiatives are provided in different regions.

Figure 8: Variations in Progress on Gender-Inclusion Over Time
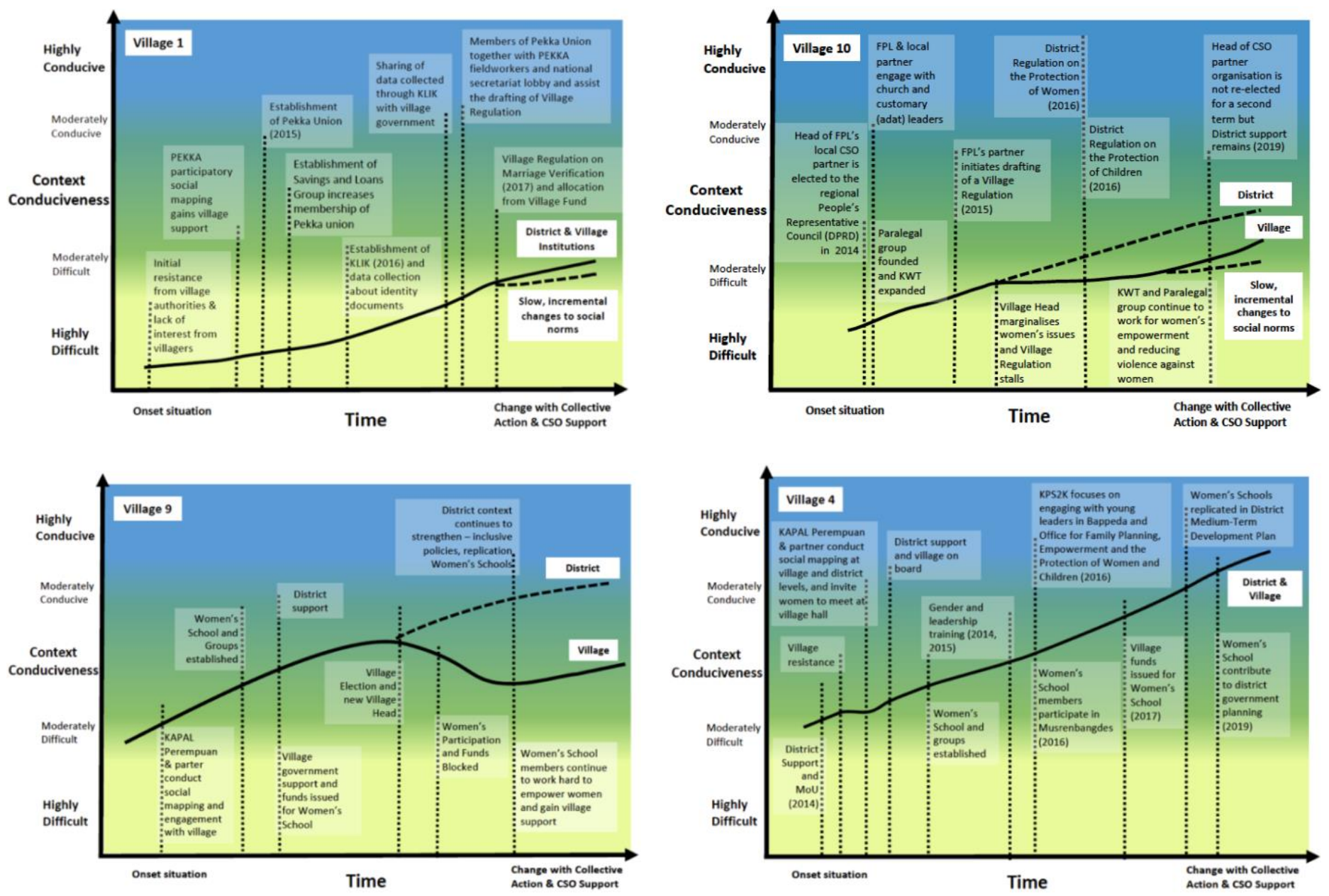

Applications

On supporting women to grow skills, networks, capacities, and influence at the grassroots level

\section{Working with and through CSOs as partners can help build gender inclusiveness, reduce inequalities and facilitate} women's networked collective influence, particularly for the most vulnerable women.

- CSOs focused on gender inclusion that build trust with and support rural village women can play an important role in opening up more opportunities for, and in facilitating, multiple forms of village women's collective action. This includes women's networked collective action with others in rural areas in Indonesia, in which CSOs can help women connect to other actors and support them (especially vulnerable women) to manage risks as they embark on processes of change that inevitably challenge power structures.

- In those study areas that did not have long term and active involvement of trusted CSOs, the study found it was more challenging for women to work collectively to bring about either formal or informal changes. There was little endogenous change already occurring in relation to women's collective action. Other programs and structures of support (such as networks of trusted facilitators) that display similar features to those of CSOs described in this research may also play a similar role.

- Both village women and CSOs are highly adaptive and resourceful in responding to variable context constraints and opportunities. Even in highly resistant contexts, with unsympathetic leadership, it is possible for grassroots women's groups to collectively act to create tangible change 
under the Village Law and in broader gender inclusion. CSO support helps this process.

- Facilitating gender awareness (for women but also in the community), strategic policy design and significant on-theground support (both by CSOs and other authoritative facilitators responsible for programs and services) helps ensure spaces are opened up for women, particularly more marginalised women to both participate and actually exercise voice and influence in practice, especially if this is not the norm.

- This does not mean all CSOs or other agencies should take the same approach-choices need to be made appropriate to the context dynamics, sectoral agenda, whether this might traverse cultural taboos, resource availability, existing networks, groups, relationships, and champions, with each having its strengths and drawbacks.

2. Gender inclusion initiatives that seek to grow grassroots skills, knowledge and rural women's influence should be introduced in carefully sequenced and supported ways, especially in the most difficult contexts.

- Focusing on improving the regulatory environment and supporting on-the-ground initiatives that enhance both women's concrete skills and broader knowledge and capacities, particularly for participation in decision-making forums, helps to increase gender inclusiveness.

- Focusing on policy and institutional environments alone is insufficient to produce lasting change on the ground-analysis found many of the policy-focused strategies were effective because they were grounded in concrete, village-level benefits for women.

- Women's influence is enhanced through programs supporting the development of practical skills and opportunities-e.g. economic, livelihood, parenting and health, and literacy skills.

\section{Ensuring diverse, inclusive membership of women from different backgrounds in women's groups and stakeholder forums} bolsters wider gender inclusion.

- In difficult contexts, drawing from existing groups at the onset of programs through social activities helps to establish a core membership of women's groups (and overcome barriers to village access), but does not ensure diversity of membership of elite and non-elite women from different backgrounds.

- There are advantages to also supporting new women's groups or informal spaces, as they create safe spaces for women outside of usual social dynamics.

- Multi-stakeholder forums and groups can be a complementary structure to women's groups and informal
- Supporting CSOs as partners in ways that allow them to expand their work and facilitate their support for village women, allows them to develop approaches that are context adaptive, relevant to the sectoral issue at hand, and sensitive to the risks for and context-specific needs of women, particularly those who are most excluded or vulnerable. Similar flexibility would be needed in other structures of support for village women that don't work with and through CSOs, as the risks for village women remain.

- CSOs tend to fill important knowledge, capacity and service gaps for policy makers who might be willing but unsure about how to go about instituting change so as to be more inclusive of women. This is often an important component of accessing and building trust in villages. While adaptable and resourceful, CSOs need funding for this work.

- Enhancing women's knowledge is also crucial, particularly sectoral knowledge, gender awareness, understanding of government administrative processes, and confidence in public speaking, negotiation, community outreach and leadership.

- Careful sequencing of grassroots support to women in different contexts is important so as to increase the likelihood of access and impact.

- Leveraging existing social networks for access and support helps with this process, as does aligning activities with the needs and priorities of the village where possible (or framing interventions as such) and supporting activities that have an economic focus in the most difficult contexts to build trust. spaces for effectively lobbying decision makers, but should be complemented by other safe, exclusive spaces for women.

- Crucial in this process is finding and building support from champions that become integrated in women's networks for collective action.

- Formally recognising women's groups in regulatory structures gives groups legitimacy, helping ensure women are invited to and included in decision-making structures.

\section{On adapting support for gender inclusion to varied subnational contexts and sectors}

\section{Tailoring policy-based interventions and development support to accommodate context and sectoral/thematic differences helps increase the likelihood of achieving gender inclusive outcomes.}

The challenges that rural women face and the barriers to gender inclusion are diverse. In seeking to address inequalities and tackle poverty, tailoring support to accommodate different and emerging context or sector-specific constraints is essential in supporting women to navigate the constraints they will likely face. For example, women who are migrant workers are embedded in international networks and require different kinds of support to homeworkers. At times this may mean directly addressing sensitive issues, at other times and in other contexts it may require more indirect approaches that effectively engage with decision makers who are often male. 
5. Customising support for women, investments, timeframes, and monitoring and evaluation metrics to be relevant to and vary according to context features helps minimise risks and to establish achievable goals.

In more conducive contexts, smaller investments in development programs or policy initiatives may be able to yield more rapid outcomes but will unlikely reflect the challenges, time and investment needed to support women in more difficult environments. Customising support for women, timeframes for progress, and monitoring and evaluation metrics to be relevant to the contexts in which initiatives take place will help tailor support for gender inclusion and ensure outcomes are both achieved and the risks for women are minimised. Plan for slow and incremental change in difficult contexts and on difficult and sensitive issues.

\section{Supporting gender inclusion initiatives for longer time frames in difficult contexts makes achieving gender inclusiveness more likely.}

The study reveals opportunities and challenges for government and non-government development programs in contexts that are not conducive to women's empowerment. These differences in progress in highly difficult contexts highlight that development partners should invest in long-term support to programs that develop foundations of trust in communities and provide external protections for women as they encounter significant resistance.
In difficult contexts, agencies should also focus on fewer villages and using heavier investments at the village level based on network and social mapping with community members. This more intensive investment should also involve embedding CSO staff (or other community support and facilitation staff) in villages. By living in or nearby villages, staff can frequently engage with women and support them to navigate context constraints.

\section{Working concurrently at district and village levels (bolstered with national-level advocacy) is critical for gender inclusive} development in rural areas, particularly under the Village Law.

It was also clear from the study that gender inclusion achievements are made by concurrently undertaking advocacy and policy support at district levels, while also embedding institutional change in on-the-ground village initiatives that provide concrete benefits for women. There were a number of examples where progress at the district level propelled women's influence and voice at the village level, or vice versa, where progress at the village level supported higher-level shifts.

Working at both levels broadens the support for-and reinforces-changes in the institutional environment. This builds resilience to ruptures and setbacks, deepening the sustainability of empowerment initiatives. It was evident in the study that working at both levels also increases the likelihood that the impacts of gender inclusion initiatives will increase over time, as broader advocacy efforts become embedded in practice through concrete activities on the ground with women. Women are then able to increasingly exercise voice and influence but also be involved in the broader advancement of gender inclusion in Indonesia. This is bolstered by national level partnerships and advocacy with government and mass social organisations to improve underlying institutional contexts.

\section{Developing rules and policies, forums, and women's spaces in governance structures/programs that incentivise inclusiveness for women helps motivate resistant actors.}

The study identified how important rules (regulations, policy, implementing guidelines) and resources (human and financial) were for helping policy makers to support women's empowerment. While formal rules are a necessary and important component of increased women's influence on the implementation of the Village Law, they are not in themselves sufficient for reducing inequalities and improving gender inclusiveness - this also entailed supporting women to have influence in power structures and decision-making processes.

- Rules in particular motivate authoritative actors and power holders who are resistant to support inclusive development and an increased role for women in decision making, although other studies have shown that 'workarounds' can result.

- Rules and regulations, nonetheless, help ensure that advancements did not easily regress with changes in leaders and other authoritative figures at different levels.
- Facilitation for communities on how to go about improving the inclusion of women in decision-making helps fill capacity and knowledge gaps.

- Formally recognising women's groups, and creating specified women's spaces in development decision making (such as Women's MusDes or Musrenbangdes), and rules to ensure inclusion in final decision-making forums will go some way to countering the resistance that village women face.

It will be important to monitor the progress of the recent 2019 Minister of Villages, Development of Disadvantaged Regions, and Transmigration Regulation, which broadens the scope of Village Fund uses to a number of themes that women have tended to prioritise when they have managed to access the fund. Oversight and accountability will be important in this process, as will be investing in community facilitation to improve inclusive decision-making. 


\section{On the COVID-19 response}

\section{Maximise opportunities for women to influence use of Village Fund in COVID-19 responses.}

It is now widely recognised around the world, that the COVID19 pandemic is impacting on women and men differently. ${ }^{\text {iii }}$ This occurs across areas of health, social and economic wellbeing, and women's participation. Women face high health risks as they make up $70 \%$ of all health and social services staff around the worldiv - and $67 \%$ of health and services staff in Indonesia. ${ }^{v}$

There is also the potential indirect health crisis as resources are diverted away from usual maternal and women's health services, something that was documented during the Ebola crisis. ${ }^{\text {vi }}$ Women are also disproportionately impacted by care giving responsibilities during the crisis with women around the world performing three times more unpaid caregiving than men. vii Domestic violence has increased in some middleincome contexts ${ }^{\text {viii, }}$ as it did during the Ebola crisis. ${ }^{\text {ix }}$

As women are more likely to be in informal and vulnerable employment, the negative economic impact of COVID-19 responses will likely disproportionately affect women. Further, in crisis, women and girls are often excluded from grassroots decision-making forums which further weakens women's participation in responses.

\section{The COVID-19 response in Indonesia}

The Government of Indonesia has initiated a number of innovative responses to the COVID-19 crisis. These are across several sectors including health, industry support, social safety nets (including basic food assistance and cash assistance) and economic recovery programs.

International and United Nations agencies have also initiated a number of responses. The World Bank, Asian Development Bank and Asian Infrastructure Investment Bank have approved financing and loans for the Government of Indonesia to respond to COVID-19. Several United Nations agencies in Indonesia, including WHO, UNICEF and UNDP have developed action plans related to the COVID-19 response with UN Women in particular supporting women and girls leading and participating in COVID-19 response planning and decisionmaking from local to national levels. Many bilateral donors, including Australia's Department of Foreign Affairs and Trade have redirected support toward the COVID-19 response.

\section{The Village Law and the COVID-19 response}

Of most interest in this policy brief is the use of the Village Fund (Dana Desa) in the COVID-19 response. Minister of Villages, Development of Disadvantaged Regions, and Transmigration Regulation No. 6/2020 (enacted on 13 April) specifically allows for Indonesian villages to respond to COVID19 pandemic using the Village Fund.

Under the new regulation, the Village Fund can be used for a wide range of COVID-19 response activities, such as the maintenance of neighbourhood facilities, including rehabilitation facilities to isolate COVID-19 victims, personal protective equipment, neighbourhood cleaning and other activities to prevent the spread of the virus, including provision of information and training.

The regulation also allows for the Village Fund to be used for direct cash transfers (BLT-Dana Desa) for those losing their livelihoods, those excluded from other social protection programs and those who have family members with chronic illnesses, requiring three people to verify that recipients are indeed poor and have not been included in other programs. Decisions on village responses under the Law are within the authority of the Village Government and decided through musyawarah desa (MusDes, village consultative forums).

The regulation provides scope for the establishment of COVID19 Village Volunteer Teams (or what is known as the village COVID-19 Taskforces), headed by the Village Head and with members from various village organisations, local public figures and authorities. The regulation does not specify requirements for general women's participation in these taskforces, nevertheless the team structure includes volunteers from village facilitators, village midwives, and Family Welfare and Empowerment organisation (PKK), which are often women-led but do not necessarily represent women's diversity and needs. Village COVID-19 Taskforces are central to decision making on who receives cash transfers.

\section{Lessons from this study for the COVID-19 response}

Learning from this study of Women's Collective Action and the Village Law, the COVID-19 crisis represents a rupture in the status quo of women's participation in grassroots decision making around the Village Law. This presents both opportunities and threats for women's voice and influence. The women's organisations involved in this study report that in areas where significant community organising had already taken place through women's groups, unions, networks, informal spaces and support for women, women in many instances were the first to move in the COVID-19 response in communities.

In these places, women have often taken on leadership roles in the COVID-19 response while also managing the challenges for themselves and their families brought on by the crisis. It is timely for agencies to further support the organisations that have helped position these women to move quickly.

Some groups are also particularly vulnerable. Partner organisations in this study report that this is particularly the case for returned migrant workers, female-headed families who often experience the highest levels of impoverishment and are not well captured in other social protection initiatives-homeworkers (as the factories and businesses they supply shut down), and for women creating livelihoods in the informal sector, among others.

In some areas where homeworkers and other women were already organised based on prior CSO support, homeworkers 
in villages have quickly developed their own small businesses, providing, for example, creatively decorated personal protective equipment such as material face masks, which are in high demand. Female-headed families have managed to be reached in the cash transfer program mentioned above, again particularly in areas where such women were members of groups. ${ }^{x}$ Other regions could learn from these experiences of the importance of community organising through women's groups of different kinds. Applying the findings of this study to the current context of responses to COVID-19, there are specific ways in which government and non-government agencies can support women to maximise opportunities for participation in Village Fund decision making.

- Working with CSOs focused on gender inclusion as partners, or other agencies, organisations and sets of actors (such as facilitators) that are trusted by and support local women, is important to counter possible gender exclusion. Many CSOs have already been actively supporting women to take on leadership roles in COVID-19 responses and to give additional support to the most vulnerable groups.

This study has highlighted the importance of CSO or other actors that are trusted by women in facilitating an increase in the decision-making power of women and women's groups. While the COVID-19 response presents significant challenges to the usual operation of CSOs they are highly adaptive-it is crucial that CSOs continue to be resourced in their work on women's collective action and influence.

- Continued support for wide-reaching, cross-cutting gender inclusion and development initiatives can augment the impacts of the COVID-19 response. Partner organisations for this study have identified the risks of pivoting all support from development partners for CSOs and from other development initiatives to the COVID-19 response. Some of the organisations working in critical healthcare and education, reproductive health education, community organising, skills development and education of the most vulnerable women, have reported that these groups are particularly vulnerable to the health risks and other pandemic affects, but funding for their wider programs has been reduced or cancelled, leaving swathes of women at greater risk. There are benefits for both wider development and the COVID-19 response by continuing to support wider-reaching, cross-cutting gender inclusion and development initiative

\section{Design risk mitigation strategies for the unintended consequences of the COVID-19 response itself.}

Women's representation in decision making in COVD-19 responses is critical. While some areas have a prior history of women's groups that have diverse, skilled, vocal and influential women, this is not uniformly the case across Indonesia, with many areas reflecting the features of the 'control' research sites in which women have long been excluded from development decision making and priorities. In these areas there is a greater likelihood that women are underrepresented in COVID-19 responses, Village Fund allocations, and in the village-level Taskforces coordinating the response. Learning from the experience of this study, even those women-led organisations that have been represented on village Taskforces may not have diverse female membership.

The role of MusDes and COVID-19 Village Volunteer Teams is crucial in Village Fund decision making in response to COVID19 , and yet to date, there have been no specific guidelines about women's involvement. Gender inclusion can be bolstered by:

- Shifting the guidelines and maximising women's participation in these forums, especially considering the disproportionate impact of COVID-19 on women (e.g. increased risk of domestic violence, loss of income, and greater burden of care).

\section{- Higher gender representation on village and other} Taskforces. This would help ensure women's needs are taken into account in the response, any unintentional risks emerging from the response itself are identified, and give women the opportunity to provide inputs on how to mitigate these risks. This includes the risks for women responsible for sustaining households (e.g. through visiting village markets), supporting ill family members, and who need to undertake other activities that may increase their encounters with community security and monitoring posts set up or strengthened by the COVID-19 response.

For many women such encounters can be frightening and negative. Higher gender representation on Taskforces will help plan for risks and to develop tailored responses, especially regarding any increases in household tensions arising with stay-at-home orders. 
i See Diprose, R., Savirani, A., Setiawan, K.M.P. and Francis, N., 2020. Women's Collective Action and the Village Law: How Women are Driving Change and Shaping Pathways for Gender-inclusive Development in Rural Indonesia. The University of Melbourne, Universitas Gadjah Mada and MAMPU. https://doi.org/10.46580/124326. Available at: www.mampu.or.id and www.demisetara.org.

ii 21 detailed life stories of women, and 12 extended process-tracing case studies of how women's collective action has influenced the implementation of Indonesia's Village Law, have been developed. For the women's life stories (available in both English and Bahasa Indonesia, with an overview by K.M.P. Setiawan, B.A. Beech Jones, R. Diprose and A. Savirani, 2020) see Setiawan, K.M.P., B.A. Beech Jones, R. Diprose and A. Savirani [Eds], 2020. Women's Journeys in Driving Change: Women's Collective Action and Village Law Implementation in Indonesia. The University of Melbourne and Universitas Gadjah Mada. https://doi.org/10.46580/124331. Available at: www.mampu.or.id. and www.demisetara.org. For the 12 process-tracing case studies (available in full in Bahasa Indonesia, with abstracts and an overview by R. Diprose, A. Savirani, A.S. Hartoto, \& K.M.P. Setiawan, 2020 available in both English and Bahasa) see Savirani, A., R. Diprose, A.S. Hartoto, and K.M.P. Setiawan [Eds], 2020. Forging Pathways for Gender-inclusive Development in Rural Indonesia: Case Studies of Women's Collective Action and Influence on Village Law Implementation [Membuka Jalan untuk Pembangunan Inklusif Gender di Daerah Perdesaan Indonesia: Bunga Rampai Kajian Aksi Kolektif Perempuan dan Pengaruhnya pada Pelaksanaan Undang-Undang Desa]. The University of Melbourne, Universitas Gadjah Mada and MAMPU. https://doi.org/10.46580/124328. Available at: www.mampu.or.id. and www.demisetara.org.

iii Haneef, C. \& A. Kalyanpur. 2020. 'Global Rapid Gender Analysis For COVID-19'. CARE and the International Rescue Committee. Available at: https://www.rescue.org/report/global-rapid-gender-analysis-covid-19.

iv Linde, A. \& A. González Laya. 2020. 'What the COVID-19 Pandemic Tells Us About Gender Equality'. World Economic Forum. Available at https://www.weforum.org/covid-action-platform/articles/what-the-covid-19-pandemic-tells-us-about-gender-equality.

$\checkmark$ Prospera 2019, cited in MAMPU COVID-19 newsletter May 2020.

vi Sochas, L., A.A. Channon, \& S. Nam. 2017. 'Counting Indirect Crisis-Related Deaths in the Context of a Low-resilience Health System: The Case of Maternal and Neonatal Health During the Ebola Epidemic in Sierra Leone'. Health Policy Plan 32 (suppl 3): iii32-39.

vii International Labour Organisation (ILO). 2018. 'Care Work and Care Jobs for the Future of Decent Work'. Available at: https://www.ilo.org/wcmsp5/groups/public/---dgreports/---dcomm/---publ/documents/publication/wcms_633135.pdf.

viii Mutavati, A., M. Zaman, \& D. Olajide. 2020. 'Fighting the 'Shadow Pandemic' of Violence Against Women \& Children during COVID-19'. African Renewal. Available at: https://www.un.org/africarenewal/web-features/coronavirus/fighting-\%E2\%80\%98shadow-pandemic\%E2\%80\%99-violence-against-womenchildren-during-covid-19.

ix Onyango, M.A. 2020. 'Sexual and Gender-based Violence during COVID-19: Lessons from Ebola' The Conversation, May 10. Available at https://theconversation.com/sexual-and-gender-based-violence-during-covid-19-lessons-from-ebola-137541.

${ }^{x}$ The Minister for Villages, Transmigration and Disadvantaged Areas Development announced to the national parliament at the end of June 2020 that $27 \%$ of the cash transfers made to date had been to female-headed families. 


\section{University Library}

\section{- M I I N E R VA \\ A gateway to Melbourne's research publications}

Minerva Access is the Institutional Repository of The University of Melbourne

Author/s:

Diprose, R;Savirani, A;Wells, T

Title:

Gender-inclusive Development and Decentralised Governance: Promoting Women's Voice and Influence through Collective Action in Rural Indonesia

Date:

2020-02-01

Citation:

Diprose, R., Savirani, A. \& Wells, T. (2020). Gender-inclusive Development and Decentralised Governance: Promoting Women's Voice and Influence through Collective Action in Rural Indonesia. The Australia-Indonesia Partnership for Gender Equality (MAMPU), The University of Melbourne and Universitas Indonesia..

Persistent Link:

http://hdl.handle.net/11343/258465 